\title{
Publishers and librarians examine scholarly communication
}

Information encounters, personal libraries, online journals, publisher-written abstracts, and natural concept query language are some of the highlights of the Society for Scholarly Publishing's Top Management Roundtable held October 3 and 4 , 1991, in Cambridge, Massachusetts. The theme of the meeting-Scholarly Communication at Workproduced a stimulating framework in which scholars and researchers spoke candidly about their information needs, communication patterns with colleagues, and their expectations of publishers and libraries.

The roundtable meeting involved the 57 participants in three half-day segments: the Scholars' Needs; the Money Flows; and Setting the Course for the Future. The meeting is an occasion for scholarly publishers to come together in a small group to grapple with an issue that is of interest and concern to the varied membership of the society.

The results of a study of the information acquisition and usage needs of scientists, commissioned by the Faxon Institute, opened the first segment. "Information encounters" is the term coined to define the activities and behaviors of scientists seeking information in published material and byverbal and electronic information. Joumals, colleagues, and books are the top three content sources reported in the survey that scientists use for work-related information. The study also revealed that libraries are perceived to have a high degree of usefulness but are not frequently used, a paradox in the current system.

The development of personal libraries by scholars is a trend touched on by a number of panelists. The personal library satisfies scholars' needs for controlling the information they use, for making discriminating choices from the increasing amount of material available, and for covering interdisciplinary areas. Librarians do not always play a role in the development of these personal libraries.

Scholars have expressed a need to find information quickly and online databases and computerized indexes help to satisfy this need. However, most of today's databases provide access to current material only. Older information in monographs, journal articles, and proceedings, etc., can be as important as the new developments whose literature is under machine control. Publishers were asked to consider providing access to older material as new information products are configured.

There are risks and concerns that scholars face dealing with computerized information and its rapid transmission. The human ability to sift and sort vast amounts of data can lead to research distortion, information overload, and anxiety. Librarians will play an important role in the scholar's future as they deal with the changing nature of wisdom, intelligence, and knowledge in a real-time environment. They will not only be guides for scholars but "information sifters." Paraphrasing Alvin Toffler in Power Shift, the person who will have power in the future will be the one who knows how to find information. The participants agreed that this is a challenging and important time for librarians.

Scholars recognize that technology has aided the increase in published material. However, the existence of more journals does not necessarily incrementally advance a discipline. Mediocre papers still get published. Peer review works well as a gatekeeping and quality system within a journal, but it does not work well between journals. The changing economic base of research and its dissemination is straining scholarly communication. Bob Bovenschulte, New England Journal of Medicine, outlined a number of trends that are affecting scholars, librarians, and publishers. A few of his major points are that technology will expedite the delivery of information, although the innovations will not prove significantly better until the prices drop; that libraries, driven to economize, will create products and services that will compete with publishers; that scholars will have more of the burden of scholarly communication placed on them and will pay a greater share of the cost or forego something; and that document delivery will develop as a substitute for books and journals, with delivery charges decreasing almost to the cost of printing.

In this environment the government mayemerge as a greater player, coordinating and subsidizing access and delivery services, an idea that did not sit well with a number of the publishers, society or commercial, participating in the meeting. It is clear that publishers will try to protect their copyright as an ownership issue and as a source of revenue. As rights shift to the users, traditional revenue models will change as well.

The concept of shifting property rights stirred much discussion among publishers and librarians at the meeting. While there is much interest in electronic publishing and network access and dissemination, there is also a great deal of uncertainty as to whether this distribution channel will work effectively to the benefit of the scholarly triumviratepublishers, scholars, and libraries.

(Cont. on page 729) 
to reimburse the institution for such use under the guidance of institutional policy.

II.E.3.b. No staff member should use at home any object or item that is a part of the library's collections or under the guardianship of the library, or use any other property, supplies, or resources of the library except for the official business of the institution. To the extent that circumstance or special policies warrant exceptions, the circumstances or policies should be a matter of written record.

\section{II.F. Confidentiality}

Special collections librarians, whose work in- volves intimate knowledge of the work of researchers, the library's relations with donors and booksellers, and other material of a confidential nature, must be scrupulous in keeping this information confidential.

II.F.1. Special collections librarians must keepconfidential information about the activities and research of their readers which they gain in performance of their professional duties.

II.F.1.a. Exceptions may be made to this provision in cases where, for the advancement of scholarship, the reader has signed a written agreement to waive any claim to confidentiality in general or in specific instances.

\section{(Scholars cont. from page 720)}

The roundtable meeting ended with a discussion on how the future may be influenced. A number of scholars presented plans for projects that would create electronic publications available for shared access. Among these are the American Association for the Advancement of Science's online medical journal, a computerized dictionary of American literary terms, and a database of astronomy literature with natural language indexing. Common to these projects are the post-publication issues of storage, physical copies made at some point in time, and archival and preservation issues.

Academic librarians are already facing these access and archival issues with established programs at a number of large research institutions. They are positioned to play a key advisory role, guiding publishers and scholars in the design of electronic products that take into consideration the information needs of future generations who will use the scholarly information we are recording and distributing today.-Patricia E. Sabosik, Editor d Publisher, Choice

\section{(IASSIST cont. from previous page)}

In the session on text file issues, John PriceWilkins, University of Michigan, gave a paper on "Text Files in Libraries: Present Foundations and Future Directions." He stressed that users of text need generalized data suitable for use with a variety of software tools, as well as access to these resources in a networked environment. Research libraries have a responsibility to build electronic collections conformant with evolving standards for text encoding and to facilitate access to these resources outside the library. The session closed with an impressive demonstration of a system developed at UM to provide access to text files.

"Electronic Products and Depository Library Programs" was another session where academic librarians presented views on providing data services within a library context. Ray Jones, University of Florida, a long-time advocate of library involvement with providing access to census data regardless of format, shared his experiences with providing services over a period of two decades. Juri Stratford, University of California at Davis, highlighted the advantages and disadvantages of U.S. depository libraries receiving a deluge of electronic products, largely numeric, on CD-ROM.

Another hallmark of IASSIST conferences is the workshops. Four half-day sessions were offered and included "Starting a Data Library," "Living with UNIX," "Financial Time Series," and "Using Interactive Graphics and Statistical Data in the Classroom." Led by Ilona Einowski, University of California at Berkeley, and Jean Stratford, University of California at Davis, the workshop on "Starting a Data Library" raised many questions for those attending. While there is no one solution or organizational structure for data libraries, the various activities involved in organizing and operating a data library were debated by participants.

I attended the conference with the support of the ACRL Professional Liaison Committee and my home institution. As a member of the IASSIST Program Committee I worked to promote academic libraries as partners in providing access to computer-readable text and social data. The academic librarians who attended the conference and presented papers assisted in reaching that goal.Diane Geraci, social science and data librarian. State University of New York at Binghamton 